\title{
Precise control of caval and hepatic vessels: Surgical technique to treat level III caval thrombus concomitant to renal cell carcinoma
}

\author{
Ming Chen, MD; Bin Xu, MD; Ning Liu, MD; Hua Jiang, MD; Yiduo Wang, MD; Yu Yang, MD; \\ Xiaowen Zhang, MD; Chao Sun, MD; Jing Liu, MD; Weidong Zhu, MD; Shuqiu Chen, MD
}

Ming Chen, Bin Xu, and Ning Liu contributed equally to this study.

Department of Urology, Affiliated Zhongda Hospital of Southeast University and Urologic Institute of Southeast University, Nanling, China

Cite as: Can Urol Assoc J 2015;9(11-12):E808-13. http://dx.doi.org/10.5489/cuaj.3074 Published online November 4, 2015.

\section{Abstract}

Introduction: We investigated the surgical techniques, safety, and prevention of complications of nephrectomy and removal of tumour thrombus for treating level III inferior vena cava (IVC) concomitant to renal cell carcinoma (RCC). We did this by precise controlling IVC and hepatic vessels without a vascular bypass.

Methods: In this series, we included 5 patients with level III IVC tumour thrombus below the hepatic vein concomitant to RCC. After precisely controlling the IVC and hepatic vessels, we then removed the thrombus en bloc with the renal vein. Blood loss volume, IVC clamping time, hypotension time, resuscitation, cardiocerebrovascular complications, and postoperative organ dysfunction were observed.

Results: Surgery was successfully performed without perioperative death. Blood loss volume was 900 to $1500 \mathrm{~mL}$, operation time was 165 to 250 minutes, vascular clamping time was 8 to 12 minutes, and intraoperative hypotension time was 9 to 12 minutes. Serious perioperative complications were not observed. Local recurrence was not observed during the 9 to 24 months of follow-up. One patient exhibited disease-free survival, 3 developed lung or liver metastasis, and 1 died 11 months after surgery.

Conclusion: Precise control of IVC and hepatic pedicle vessels, without vascular bypass, is a safe and effective surgical treatment for level III tumor thrombus below the hepatic vein concomitant to RCC. The procedure was conducted without increased risks of intraoperative hypotensive shock, difficult resuscitation, pulmonary embolism, and multiple organ dysfunctions.

\section{Introduction}

Inferior vena cava (IVC) tumour thrombus occurs in $4 \%$ to $10 \%$ of patients with renal cell carcinoma (RCC). ${ }^{1-4}$ Surgically treating this condition was previously not recommended because of various surgical complications. However, complete removal of the IVC tumour thrombus has become possible with surgical techniques, especially veno-venous bypass (VVBP), cardio-pulmonary bypass (CPBP), and deep hypothermic circulatory arrest (DHCA). With these, surgical complications and mortality have significantly declined. However, local and systemic progression rates in patients with levels III and IV tumour thrombus are high, and survival rates remain low. The 5 -year overall survival across stages ranges from $30 \%$ to $60 \%{ }^{5-8}$ Cases with lymph node involvement or distant metastasis are associated with poor prognosis. ${ }^{9}$ Previous studies reported that radical nephrectomy and removal of thrombus carries a mortality rate of $5 \%$ to $12.5 \%$, depending on concomitant diseases and characteristics of the tumour thrombus. ${ }^{8,10-12}$ Moreover, a 5-year survival rate of about $38 \%$ was noted. However, the 5 -year disease-free survival rate was only $8.9 \%$, and overall prognosis was poor. ${ }^{4,10}$ The removal of levels I and II tumour thrombus can be performed after establishing a bloodless surgical area by dissociating and occluding the IVC, lumbar vein, and contralateral renal vein. A wide range of vascular control, VVBP, CPBP or DHCA is required for levels III and IV tumour thrombus. ${ }^{13}$

There are differing opinions on how to approach a level III tumour thrombus. At our institution, we routinely collaborate with hepatobiliary surgeons to ensure precise controlling of the suprahepatic IVC, hepatic pedicle, infrahepatic IVC and surrounding blood vessels; we then performed an infra-hepatic cavotomy and removed the thrombus en bloc without carrying out VVBP, CPBP or DHCA. This surgical approach is complex, and meticulous detachment and multidisciplinary collaboration are required. This paper represents our surgical technique in 5 consecutively treated patients affected by IVC tumour thrombus with RCC. 


\section{Methods}

We evaluated the medical records of 5 patients ( 3 males, 2 females) with level III IVC tumour thrombus below the hepatic vein concomitant to right RCC, who underwent surgery between November 2011 and January 2014 at out institution. The mean age was $59.2 \pm 12.2$ years (range: $38-76$ ). The mean tumour diameter was $12.8 \pm 3.4 \mathrm{~cm}$ (range: $6-17$ ) and the mean size of the tumour thrombus in the proximal end IVC was $11.6 \pm 1.9 \mathrm{~cm}$ (range: 9-15). Preoperative chest, abdomen, and pelvic computed tomography (CT) scan, upper abdominal 3-dimensional imaging, and IVC angiography were performed on all patients (Fig. 1). Distant metastases were not observed in patients before surgery.

An inverse " $\mathrm{L}$ " incision on the middle of the abdomen was performed from below the xiphoid to the umbilicus and then perpendicularly to the right mid-axillary line (Fig. 2, part A). The abdominal cavity was then exposed, and the duodenum, colon, and pancreatic head were pushed to the left side using the Kocher maneuver. The kidney, tumour, and renal artery were dissociated. In addition, the lymph nodes between the IVC and the aorta were dissected after removing the tumour thrombus. This procedure was performed to avoid stimulating the IVC when lymph nodes were difficult to isolate or when the tumour was too large. Next, the contralateral renal vein and the subhepatic IVC were isolated $5 \mathrm{~cm}$ below the renal vein (Fig. 2, part B). The thicker lumbar veins and the first hepatic portal were also dissociated. Meanwhile, the falciform, triangular, and hepatogastric ligaments were severed with the assistance of a hepatobiliary surgeon (Fig. 2, part C). The peritoneum under the diaphragmatic muscle and the fascia fibrous tissue surrounding the IVC above the liver were fully isolated to expose the diaphragmatic surface of the liver, the hepatic vein, and the supra-hepatic IVC (Fig. 2, part D). The tissues surrounding the IVC at the posterior border of the liver were isolated, and the IVC subsidiary veins were dissociated and ligated. The surgical tape was preserved for the first hepatic portal. The IVC below the renal vein, the contralateral renal vein, and the supra-hepatic IVC were clamped as close as possible to the diaphragm. The thicker lumbar vein was occluded using a small non-invasive vessel clamp. Augmentation preloading was then performed, and the vasoactive drugs were prepared. The surgical tape was tightened to block blood flow into the liver and the IVC. An incision was done on the IVC wall from the site where the right renal vein joins the IVC to the proximal end. The whole tumour thrombus was rapidly removed, along with the right kidney (Fig. 2, part F).

The vena cava were then inspected and rinsed with heparin solution. Continuous suture of the IVC incision was performed using a 5/0 vascular suture, and the air was

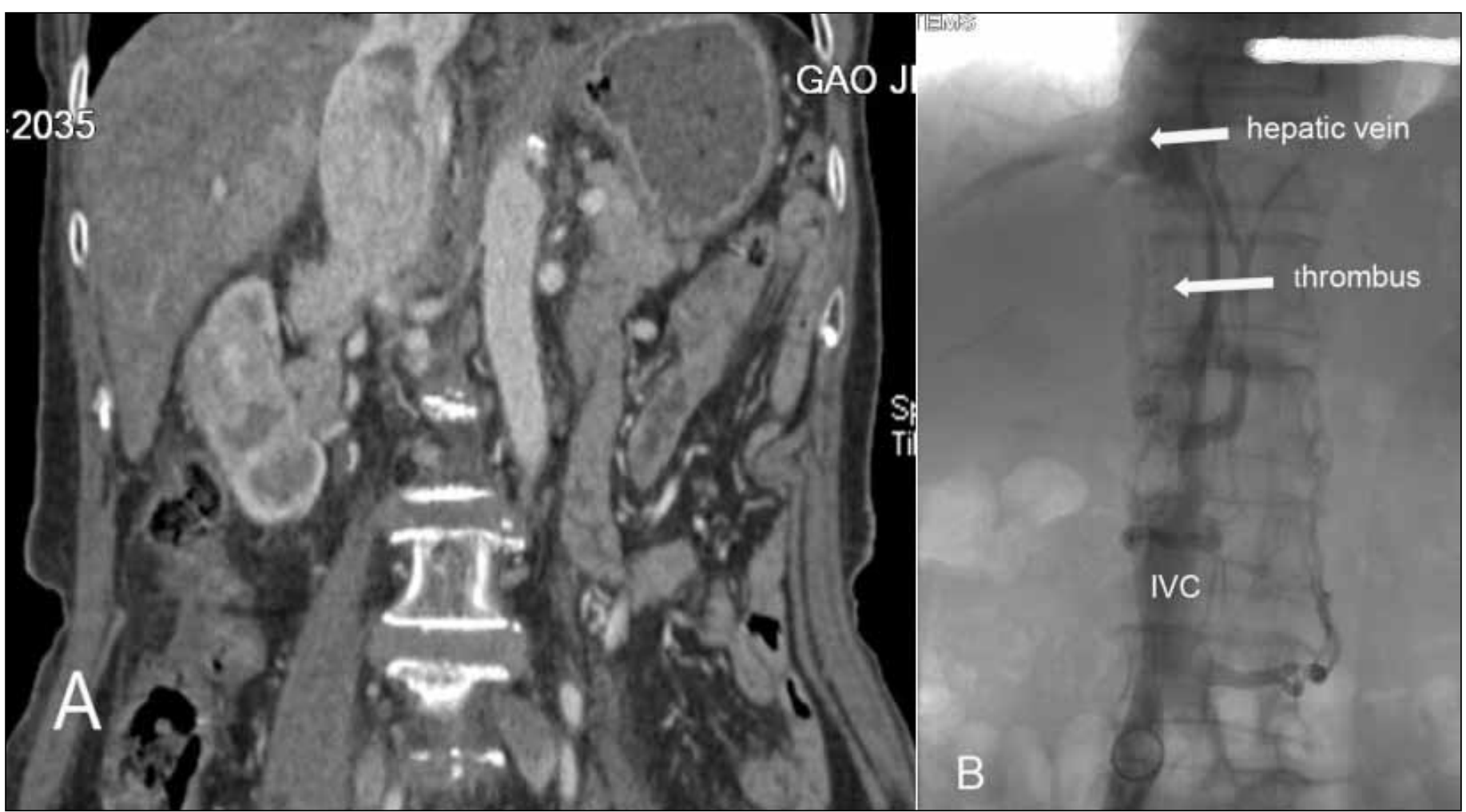

Fig. 1. Computed tomography scan (A) and inferior vena cava (IVC) angiography (B) showing tumour thrombus in IVC below the hepatic vein. 
exhausted (Fig. 2, part E). The surgical tape was removed to let blood flow and blood pressure and organ perfusion normalized soon thereafter.

\section{Results}

Five patients underwent radical surgical treatment (Table 1). The incision on the IVC ranged from 8 to $10 \mathrm{~cm}$ long and the time of the IVC suture was 4 to 6 minutes. Moreover, the duration of intraoperative hypotension was 9 to 12 minutes, and the invasive arterial blood pressure was between $65-75 \mathrm{mmHg} / 40-50 \mathrm{mmHg}$. The heart rate was between 105 and 138. Infiltration of the IVC was not observed, and the tumour thrombus was intact without rupture. All patients were successfully resuscitated without intraoperative death.

All patients exhibited transient elevation of transaminases from 60 to $186 \mathrm{U} / \mathrm{L}$, which returned to normal levels after 2 days. Moreover, the bilirubin levels were normal. The serum creatinine $(\mathrm{Scr})$ levels of 4 patients increased from
$185 \mu \mathrm{mol} / \mathrm{L}$ to $265 \mu \mathrm{mol} / \mathrm{L}$, and returned to normal within 1 week and fifth patient remained constant at $180 \mu \mathrm{mol} / \mathrm{L}$. Ischemic brain injury, myocardial infarction, or pulmonary embolism was not observed. Pathological examinations confirmed the presence of cancerous tissues in all of the thrombus, clear cell carcinoma in 4 cases, and papillary adenocarcinoma in 1 case. All 5 patients had fatty infiltration of the renal capsule, while 1 case showed renal hilar lymph node infiltration. Patients stayed in hospital for 14 to 21 days postoperatively. During the follow-up period between 9 and 24 months, 1 patient died 11 months postoperatively because of multiple metastases in both lungs. Three patients showed distant metastases (pulmonary, liver), and 1 patient remained disease free.

\section{Discussion}

RCC can spread to the renal vein and extend to the proximal end of the IVC to form IVC tumour thrombus, which can

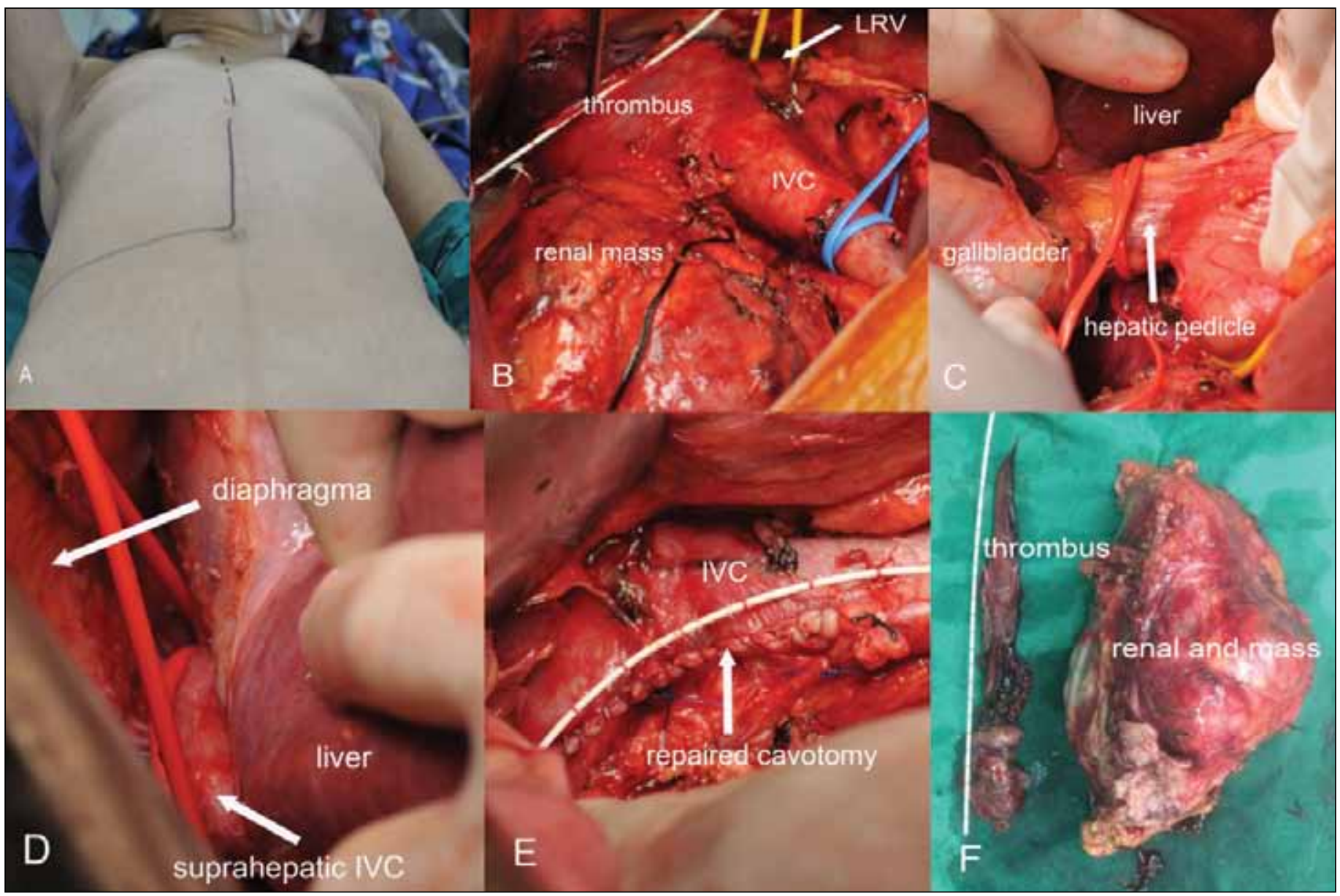

Fig. 2. Intraoperative findings of a 74-year-old female patient with level III tumour thrombus concomitant to right renal cell carcinoma. (A) Inverse "L" incision, (B) exposure of tumour and isolation of subhepatic inferior vena cava (IVC) and contralateral renal vein, (C) exposure and isolation of first hepatic pedicle, (D) isolation of diaphragmatic surface of liver and suprahepatic IVC, (E) suture of IVC incision after excision of tumour and tumour thrombus, (F) excised tumour thrombus form renal vein extended into proximal and distal end of IVC about $21 \mathrm{~cm}$. 
Surgical treatment for caval thrombus concomitant to RCC

\begin{tabular}{lcccccc}
\hline \multicolumn{2}{l}{ Table 1. Operation outcome } \\
\hline Patient & $\begin{array}{c}\text { OT } \\
\text { (min) }\end{array}$ & Time of IVC and HD clamping & $\begin{array}{c}\text { Time of hypotension } \\
\text { (min) }\end{array}$ & $\begin{array}{c}\text { EBL } \\
\text { (mL) }\end{array}$ & $\begin{array}{c}\text { Time of Rs } \\
\text { (min) }\end{array}$ & $\begin{array}{c}\text { Major complications } \\
\text { (min) }\end{array}$ \\
\hline 1 & 250 & 10 & 11 & 1100 & 125 & No \\
2 & 165 & 7 & 10 & 900 & 168 & No \\
3 & 220 & 8 & 9 & 1500 & 180 & No \\
4 & 180 & 8 & 12 & 950 & 130 & No \\
5 & 195 & 10 & 11 & 1250 & 135 & No \\
\hline OT: operation time; IVC: inferior vena cava; HD: hepatic pedicle; EBL: estimate blood loss; Rs: resuscitation. &
\end{tabular}

extend into the heart atrium (level IV). Establishing vascular bypass, such as CPBP or VVBP, or a combination of vascular bypass with piggy-back fashion liver transplantation is required in most cases. ${ }^{14}$ Thoraco-abdominal incision can satisfactorily expose renal masses and post- and suprahepatic IVC. Complete isolation of post- and supra-hepatic IVC controls bleeding and removes the tumour thrombus, thereby reducing risks of uncontrollable bleeding, residual tumour thrombus, and pulmonary embolism. Although thoraco-abdominal incision is widely accepted, this procedure cannot effectively reduce operative risks when post-hepatic IVC and surrounding subsidiary veins are not isolated..$^{15}$

The key steps in this technique are to completely isolate the retro- and supra-hepatic IVC, and the first hepatic pedicle, and to clamp the IVC and hepatic pedicle to ensure a bloodless surgical field for thrombectomy and vascular suture. Furthermore, clamping time should be as short as possible to reduce ischemia-related complications. The difficulty occurs when the level III tumour thrombus exceeds the hepatic vein level and reaches below the diaphragm. This condition may rupture and shed the tumour thrombus. Therefore, this technique is inappropriate. Preloading and maintaining blood pressure are necessary during the procedure. To protect liver function, IVC and first hepatic pedicle clamping time should be controlled within $10 \mathrm{~min}-$ utes. Intraoperative hypotension did not significantly affect the contralateral renal perfusion because of the clamping of the renal vein. The elevation of postoperative serum creatinine was associated with incomplete compensation of the solitary kidney. Cardio-cerebrovascular accidents, including hypotension, cerebral ischemic injury, cerebral infarction, myocardial infarction, and pulmonary embolism, are risks associated with this technique. These risks can be effectively prevented by augmenting the preload with vasoactive drugs, shortening the clamping time, and completely removing the tumour thrombus.

Applying VVBP, CPBP, or DHCA during the procedure can reduce bleeding and help completely remove the tumour thrombus without causing fracture and pulmonary embolism. ${ }^{16,17}$ Successfully isolating the suprahepatic and posthepatic IVC, which are anatomically delicate and contain highly vascularized tissues. A short suprahepatic IVC always contains several variable subsidiary veins. The isolation of
IVC in these areas is a major difficulty in this technique. Therefore, experienced hepatobiliary surgeons are required to perform this procedure. If the IVC in these areas are not well-isolated and controlled to establish a bloodless surgical field, rupture and residue of tumor thrombus may occur. Subsidiary veins of IVC should be isolated and ligated carefully to effectively reduce bleeding, avoid uncontrollable bleeding, and ensure a bloodless surgical field. Ligating or occluding adrenal vein and lumbar vein is also an extremely important procedure. Long-term blockage of IVC because of tumour thrombus may cause sufficient reflux of collateral veins, which is one of the main causes of bleeding and unclear surgical field during thrombectomy. In one case of thrombectomy, obvious bleeding after the incision of IVC was caused by uncontrolled lumbar vein. Therefore, the lumbar vein should be isolated and occluded if necessary before incising the IVC.

Level III and IV tumour thrombectomy requires full exposure of posthepatic IVC. The IVC wall should also be excised when vessel wall infiltration is suspected. However, in our cases, local recurrence of tumour did not significantly correlate with IVC wall infiltration. Postoperatively, the overall survival and disease-free survival were not affected by the local tumour recurrence. Tumour location is important in determining postoperative local recurrence. This may be associated with the left kidney artery, superior mesenteric artery, and surrounding tissues that cannot be completely resected. ${ }^{10,18}$

The IVC lumen was rapidly flushed with heparin solution and the suction was cleaned thoroughly after the tumour thrombus was removed. This process can prevent the development of residual thrombus fragments. The renal hilar lymph and para-aortic lymph nodes were then isolated and excised. The right kidney artery was also completely excised from the aortic root.

Local recurrence was not observed during the postoperative follow-up in our 5 patients. We believe that the tumour thrombus can be completely removed without increasing the risk of rupture and residue when the suprahepatic IVC is fully controlled. Preoperative CT, magnetic resonance imaging, or trans-esophageal ultrasonography cannot fully reveal wall infiltration. ${ }^{19}$ Therefore, a careful intraoperative inspection of the IVC for the possibility of tumour invasion 
is highly required and any infiltrated IVC could be removed simultaneously. IVC wall resection or substitution by artificial blood vessels is required in patients that exhibit IVC infiltration. Vascular bypass can also be established at any time intraoperatively when necessary.

Preoperative applications of renal artery embolization and IVC filter are valuable. Renal artery embolization is mainly used to confirm tumour blood supply, control preoperative tumor bleeding, reduce intraoperative bleeding, and preferentially treat renal vein intraoperation. It is safe and effective; ${ }^{20}$ however it has side effects, such as severe pain, fever, and edema of tissues around the tumour and renal artery. Renal artery ligation and dissection can be performed after excising the renal vein and tumour thrombus. Only one case of renal artery embolization was performed preoperatively to control serious bleeding and correct anemia.

Pulmonary embolism is a serious complications. Preoperative placement of vena cava filters at the proximal end of the tumour thrombus can effectively prevent it. ${ }^{21}$ IVC filters are not routinely used in most thoraco-abdominal or abdomimal incisions with or without CPBP, VVBP, or DCHA. ${ }^{14,17,22-24}$ Measures, such as avoiding violent isolation of IVC, ensuring clear bloodless surgical field, removing the tumor thrombus entirely, rinsing the IVC lumen with heparin solution, are importance in preventing a pulmonary embolism. Insertion of IVC filters also cause trauma to patients and should be removed after surgery or anticoagulation therapy. ${ }^{21}$ Furthermore, IVC filters are costly and are therefore not recommended for routine use.

\section{Conclusions}

Precise isolation and control of the hepatic pedicle and suprahepatic IVC is a safe and effective technique to treat patients with level III IVC tumour thrombus below the hepatic vein concomitant to RCC. This strategy excises the renal tumour and tumour thrombus en bloc and avoids the VVBP, CPBP or DHCA, without increasing intraoperative blood loss and complications. The cost is also comparatively low. However, they are not recommended for tumour thrombus that exceeds the hepatic vein level. Our study has its limitations, including the small number of patients. The strategy we used should be further investigated in clinical research using a large sample size and an extended follow-up period.

Acknowledgements: This study was funded by the National Natural Science Fund of China (No. 81370849, 81202034), the Clinical Medicine Technology Project of Jiangsu Science and Technology Department (No. BL2013032), and The Basic Research Support Project of Southeast University (№. 2242015K40002).
Competing interests: The authors declare no competing financial or personal interests.

This paper has been peer-reviewed.

\section{References}

1. Woodruff DY, Veldhuizen PV, Muehlebach G, et al. The perioperative management of an inferior vena caval tumor thrombus in patients with renal cell carcinoma. Urol Oncol 2013;31:517-21. http://dx.doi. org/10.1016/i.urolonc.2011.03.006

2. Abbasi A, Johnson TV, Ying K, et al. Duplicated vena cava with tumor thrombus from renal cancer: Use of venogram for safer operative planning. Urology 2012;79:e57-8. http://dx.doi.org/10.1016/i. urology.2011.06.044

3. Rabbani F, Hakimian P, Reuter VE, et al. Renal vein or inferior vena caval extension in patients with renal cortical tumors: impact of tumor histology. J Urol 2004;171:1057-61. http://dx.doi.org/10.1097/01. iu.0000112885.66352.e2

4. Blute $M L$, Leibovich $B C$, Lohse $C M$, et al. The Mayo Clinic experience with surgical management, complications and outcome for patients with renal cell carcinoma and venous tumour thrombus. BJU Int 2004;94:33-41. http://dx.doi.org/10.1111/j.1464-410X.2004.04897.x

5. Ficarra V, Galfano A, Guille $F$, et al. A new staging system for locally advanced (p T3-4) renal cell carcinoma: A multicenter European study including 2,000 patients. J Urology 2007;178:418-23. http:// dx.doi.org/10.1016/i.juro.2007.03.104

6. Al Otaibi M, Abou Youssif $T$, Alkhaldi A, et al. Renal cell carcinoma with inferior vena caval extention: Impact of tumour extent on surgical outcome. BJU Int 2009,104:1467-70. http://dx.doi.org/10.1111/i.1464410X.2009.08575.X

7. Ciancio $G$, Manoharan $M$, Katkoori $D$, et al. Long-term survival in patients undergoing radical nephrectomy and inferior vena cava thrombectomy: Single-center experience. Eur Urol 2010,57:667-72. http://dx.doi. org/10.1016/i.eururo.2009.06.009

8. Parra J, Drouin SJ, Hupertan V, et al. Oncological outcomes in patients undergoing radical nephrectomy and vena cava thrombectomy for renal cell carcinoma with venous extension: A single-centre experience. Eur J Surg Oncol 2011;37:422-8. http://dx.doi.org/10.1016/i.eiso.2011.01.028

9. Neves RJ, Zincke H. Surgical treatment of renal cancer with vena cava extension. Br J Urol 1987;59:390-5. http://dx.doi.org/10.1111/i.1464-410X.1987.tb04832.x

10. Rigaud J, Hetet JF, Braud G, et al. Surgical care, morbidity, mortality and follow-up after nephrectomy for renal cancer with extension of tumor thrombus into the inferior vena cava: Retrospective study since 1990s. Eur Urol 2006:50:302-10. http://dx.doi.org/10.1016/i.eururo.2006.02.065

11. Haferkamp A, Bastian PJ, Jakobi $\mathrm{H}$, et al. Renal cell carcinoma with tumor thrombus extension into the vena cava: Prospective long-term followup. J Urol 2007;177:1703-8. http://dx.doi.org/10.1016/i. juro.2007.01.039

12. Wagner $B$, Patard JJ, Mejean $A$, et al. Prognostic value of renal vein and inferior vena cava involvement in renal cell carcinoma. Eur Urol 2009;55:452-60. http://dx.doi.org/10.1016/i.eururo.2008.07.053 $47(05) 63931-6$

13. Vaidya $A$, Ciancio $G$, Soloway $M$. Surgical techniques for treating a renal neoplasm invading the inferior vena cava. J Urol 2003;169:435-44. http://dx.doi.org/10.1016/S0022-53

14. Ciancio G, Gonzalez J, Shirodkar SP, et al. Liver transplantation techniques for the surgical management of renal cell carcinoma with tumor thrombus in the inferior vena cava: Step-by-step description. Eur Urol 2011;59:401-6. http://dx.doi.org/10.1016/i.eururo.2010.07.028

15. Skinner DG, Pritchett TR, Lieskovsky $G$, et al. Vena caval involvement by renal cell carcinoma. Surgical resection provides meaningful long-term survival. Ann Surg 1989;210:387-94. http://dx.doi. org/10.1097/00000658-198909000-00014

16. Marshall FF, Reitz BA, Diamond DA. A new technique for management of renal cell carcinoma involving the right atrium: Hypothermia and cardiac arrest. J Urol 1984;131:103-7.

17. Lawindy SM, Kurian T, Kim T, et al. Important surgical considerations in the management of renal cell carcinoma (RCC) with inferior vena cava (IVC) tumour thrombus. BJU Int 2012;110:926-39. http:// dx.doi.org/10.1111/i.1464-410X.2012.11174.x

18. Thiel $D D$, Lohse $C M$, Arnold ML, et al. Does left side renal cell carcinoma (RCC) with renal vein/vena cava thrombus predict worse prognosis than equivalent right side RCC tumor thrombus? Int Urol Nephrol 2012;44:1005-12. http://dx.doi.org/10.1007/s1 1255-012-0168-2 
Surgical treatment for caval thrombus concomitant to RCC

19. Guo HF, Song $Y, N a$ YQ. Value of abdominal ultrasound scan, $C T$ and MRI for diagnosing inferior veno cava tumour thrombus in renal cell carcinoma. Chin Med I (Engl) 2009;122:2299-302.

20. Ciancio G, Vaidya A, Soloway M. Early ligation of the renal artery using the posterior approach: A basic surgical concept reinforced during resection of large hypervascular renal cell carcinoma with or without inferior vena cava thrombus. BJU Int 2003;92:488-9. http://dx.doi.org/10.1046/j.1464410X.2003.04372.x

21. Feng $X, B a 0$ J, Jing $Z$, et al. Tempofilter II for tumor emboli prevention during radical nephrectomy and inferior vena cava thrombus resection for renal cell carcinoma. J Surg Oncol 2009;100:159-62. http:// dx.doi.org/10.1002/iso.21303

22. Gallucci $M$, Borzomati $D$, Flammia $G$, et al. Liver harvesting surgical technique for the treatment of retro-hepatic caval thrombosis concomitant to renal cell carcinoma: Perioperative and long-term results in 15 patients without mortality. Eur Urol 2004;45:194-202. http://dx.doi.org/10.1016/i.eururo.2003.09.004
23. Caso J, Tidwell J, Tsivian $M$, et al. Stapled renal vein with in situ tumor thrombus: A useful intraoperative maneuver to facilitate radical nephrectomy and inferior vena cava thrombectomy. Urology 2011;77:21722. http://dx.doi.org/10.1016/j.urology.2010.02.047

24. Toren $\mathrm{P}$, Abouassaly $\mathrm{R}$, Timilshina $\mathrm{N}$, et al. Results of a national population-based study of outcomes of surgery for renal tumors associated with inferior vena cava thrombus. Urology 2013;82:572-7. http:// dx.doi.org/10.1016/j.urology.2013.04.054

Correspondence: Dr. Shuqiu Chen, 87 Dingiiaqiao Road, Nan Jing, 210009, China; chenshuqiuseu@163.com 